\title{
Treatment of Epilation- Related Postinflammatory Hyperpigmentation Using a 1,927-nm Thulium Fiber Fractional Laser
}

Keywords: Epilation; Postinflammatory hyperpigmentation; 1,927 $\mathrm{nm}$ thulium fiber fractional laser

\begin{abstract}
Postinflammatory hyperpigmentation $(\mathrm{PIH})$ is a common problem after cosmetic procedures and successful treatment of PIH remains challenging. We report the case of a 33-year-old man who presented with hyper-pigmented skin lesions on his legs that persisted for 6 months following laser hair removal. We used a 1,927-nm thulium fiber laser to treat the lesions, resulting in near complete resolution after five session over a 1 month interval.
\end{abstract}

\section{Introduction}

The development of postinflammatory hyperpigmentation (PIH) after cosmetic procedures, particularly those that employ lasers and chemical peels, is always a concern, especially in darker skin types. Radmanesh et al. reported that PIH is a major complication of intense pulsed light hair removal therapy [1]. PIH can last from months to years and may cause significant social and emotional stress to patients. Although many treatment modalities (e.g. topical bleaching agents, chemical peels, lights, and lasers) have been developed for PIH, its management is challenging due to its recurrent and refractory nature [2].

Here, we report a case of epilation-related PIH successfully treated by a $1,927-\mathrm{nm}$ thulium fiber laser.

\section{Case Report}

A 33 year-old man with Fitzpatrick skin type IV presented to our clinic with a 6-month history of brown macules and patches on the both legs (Figure 1A). He stated that the pigmentation occurred after laser hair removal on the area. He had been using several topical treatments, including hydroquinone $4 \%$, tretinoin, and arbutin without any improvement. He was diagnosed with PIH and laser treatment was recommended. We used a 1,927-nm thulium fiber fractional laser (Fraxel re:store Dual, Solta Medical Inc., Hayward, CA, USA) for 5 sessions at $5 \mathrm{~mJ} / \mathrm{cm}^{2}$, with $30-35 \%$ surface area coverage and 8 passes with 1 -month intervals between treatments. The patient was instructed to avoid sun exposure after the laser treatment and a moisturizer was applied over the area twice daily. After 5 treatments, the lesions had markedly resolved (Figure 1B).

\section{Discussion}

Postinflammatory hyperpigmentation (PIH) is a reactive

\section{Journal of}

\section{Clinical \& Investigative} Dermatology

\section{Sang Ju Lee ${ }^{1}$, Won Jong $\mathrm{Oh}^{2}$, Kui Young Park ${ }^{2 *}$, Seong Jun $\mathrm{Seo}^{2}$, Chang Kwun Hong ${ }^{2}$ and Won Soon Chung ${ }^{1}$ \\ ${ }^{1}$ Yonsei Star Skin and Laser Clinic, Seoul, Korea \\ ${ }^{2}$ Departments of Dermatology, Chung-Ang University College of Medicine, Seoul, South Korea}

\section{*Address for Correspondence}

Kui Young Park, M.D., Department of Dermatology, Chung-Ang University Hospital, Seoul, Korea 224-1 Heukseok-dong, Dongjak-gu, Seoul 156755, Korea, Fax: +82.2-823-1049; E-mail: kyky@medimail.co.kr

Submission: 09 June 2015

Accepted: 04 August 2015

Published: 10 August 2015

Copyright: ( 2015 Park KY, et al. This is an open access article distributed under the Creative Commons Attribution License, which permits unrestricted use, distribution, and reproduction in any medium, provided the original work is properly cited.

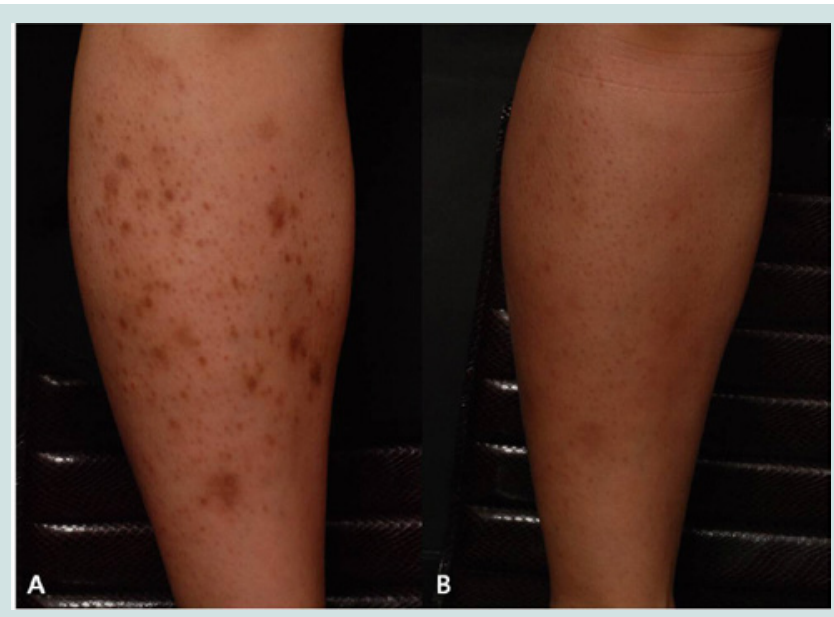

Figure 1: (A) Postinflammatory hyperpigmentation on the leg after laser hair removal. (B) After 5 treatments with a 1,927-nm thulium fiber laser.

hypermelanosis of the skin that occurs as a consequence of various cutaneous disorders as well as therapeutic interventions. PIH is benign, but is of particular concern in Asian patients because the treatment of PIH tends to be difficult and prolonged in these populations. PIH commonly occurs in Fitzpatrick skin types III to VI like the present case, and can have a considerable impact on quality of life. The majority of cases will improve spontaneously, but this can take months or even years to resolve and in some cases can be permanent. Treatment may be prolonged, lasting 6 to 12 months or longer for adequate restoration of normal pigmentation.

Treatment modalities consist of a variety of medications and procedures. These include topical bleaching agents, such as hydroquinone, azelaic acid, kojic acid, retinoids, vitamin $\mathrm{C}$, chemical peels, laser therapy, and sunscreens. It has been reported that treatment with the Q-switched ruby laser, low-dose Q-switched Nd:YAG laser, 579-/511-nm copper bromide laser, and fractional 
Citation: Lee SJ, Oh WJ, Park KY, Seo SJ, Hong CK, et al. Treatment of Epilation-Related Postinflammatory Hyperpigmentation Using a 1,927nm Thulium Fiber Fractional Laser. J Clin Investigat Dermatol. 2015;3(1): 2.

ISSN: 2373-1044

1550-nm erbium-doped fiber laser improve PIH. However, it is important to note that these same therapeutic modalities may also play a role in causing PIH [2-5].

The exact pathogenesis of this condition is unknown, PIH might be caused by mechanisms that occur in epidermal or dermal melanosis. The epidermal inflammatory response results in the release and subsequent oxidation of arachidonic acid to prostaglandins, leukotrienes, and other products. These products of inflammation alter the activity of both immune cells and melanocytes. Specifically, inflammatory products stimulate epidermal melanocytes, causing increased synthesis of melanin and a subsequent increase in transfer of pigment to surrounding keratinocytes. Such increased stimulation and transfer of melanin granules results in epidermal hypermelanosis. Dermal melanosis occurs when inflammation disrupts the basal cell layer, causing melanin pigment to be released and then trapped within macrophages in the papillary dermis, also known as pigmentary incontinence $[2,6]$.

Fractional photothermolysis may be used to treat postinflammatory hyperpigmentation. Fractional photothermolysis is a technology whereby thermal columns of injury in the dermis are created and surrounded by zones of undisturbed tissue. This allows for rapid healing of the treated area through epidermal cell migration from adjacent viable epidermis aided by the intact stratum corneum. The mechanism by which the melanin in PIH is eliminated may involve the extrusion and transepidermal vacuolar elimination of dermal and epidermal content, known as microscopic epidermal necrotic debris, through a compromised dermal-epidermal junction. Fractional photothermolysis initiates this transport system [3,7]. Polder et al. reported that using a $1,927-\mathrm{nm}$ fractional thulium fiber laser was a safe and effective treatment for nonfacial photo damage [8]. Other studies also reported the successful use of the 1,927-nm fractional thulium laser for the management of melasma $[9,10]$. However there is limited clinical data using this modality for the treatment of Lee et al. reported use of the $1,927-\mathrm{nm}$ fractional thulium laser in a patient with prolonged PIH following cupping therapy [11]. They treated by laser set at a fluence of 5-10 mJ per micro-beam, eight passes were made over the lesion during each session and total four sessions with 4 -week intervals. It showed marked improvement at 1-month follow-up after completion of four sessions of treatment. This laser more effectively targets superficial skin layers for faster clearance of pigment, whereas the previous 1,550 -nm fractional laser is ideal for deeper skin lesions. The superficial targeting in combination with the integrated cooling provides patients with improved comfort during treatment.

In this case report, epilation-related PIH was successfully treated using a 1,927-nm thulium fiber laser. Further controlled studies are warranted to better understand the efficacy, longevity, and optimal laser settings for the treatment of PIH.

\section{References}

1. Radmanesh M, Azar-Beig M, Abtahian A, Naderi AH (2008) Burning paradoxical hypertrichosis, leukotrichia and folliculitis are four major complications of intense pulsed light hair removal therapy. J Dermatolog Treat 19: 360-363.

2. Callender VD, St Surin-Lord S, Davis EC, Maclin M (2011) Postinflammatory hyperpigmentation: etiologic and therapeutic considerations. Am J Clin Dermatol 12: 87-99.

3. Katz TM, Goldberg LH, Firoz BF, Friedman PM (2009) Fractiona photothermolysis for the treatment of postinflammatory hyperpigmentation. Dermatol Surg 35: 1844-1848

4. Cho SB, Park SJ, Kim JS, Kim MJ, Bu TS (2009) Treatment of postinflammatory hyperpigmentation using 1064-nm Q-switched Nd:YAG laser with low fluence: report of three cases. J Eur Acad Dermatol Venereol 23: 1206-1207

5. Park KY, Choi SY, Mun SK, Kim BJ, Kim MN (2014) Combined treatment with 578-/511-nm copper bromide laser and light-emitting diodes for post-laser pigmentation: a report of two cases. Dermatol Ther 27: 121-125.

6. Cardinali G, Kovacs D, Picardo M (2012) Mechanisms underlying postinflammatory hyperpigmentation: lessons from solar lentigo. Ann Dermatol Venereol 139 Suppl 4: S148-S152.

7. Oram Y, Akkaya AD (2014) Refractory postinflammatory hyperpigmentation treated fractional CO2 laser. J Clin Aesthet Dermatol 7: 42-44.

8. Polder KD, Harrison A, Eubanks LE, Bruce S (2011) 1,927-nm fractiona thulium fiber laser for the treatment of nonfacial photodamage: a pilot study. Dermatol Surg 37: 342-348.

9. Ho SG, Yeung CK, Chan NP, Shek SY, Chan HH (2013) A retrospective study of the management of Chinese melasma patients using a $1927 \mathrm{~nm}$ fractional thulium fiber laser. J Cosmet Laser Ther 15: 200-206.

10. Niwa Massaki AB, Eimpunth S, Fabi SG, Guiah I, Groff W, et al. (2013) Treatment of melasma with the 1,927-nm fractional thulium fiber laser: a retrospective analysis of 20 cases with long-term follow-up. Lasers Surg Med 45: 95-101.

11. Lee SJ, Chung WS, Lee JD, Kim HS (2014) A patient with cupping-related post-inflammatory hyperpigmentation successfully treated with a $1,927 \mathrm{~nm}$ thulium fiber fractional laser. J Cosmet Laser Ther 16: 66-68. 